\title{
Vapor Pressure of Nitrogen ${ }^{1}$
}

\author{
George T. Armstrong
}

\begin{abstract}
The vapor pressure of nitrogen has been measured in the liquid range below the normal boiling point and can be represented by $\log P(\mathrm{~mm})=6.49594-255.821 /(T-6.600)$. The normal boiling point calculated from this equation is $77.364^{\circ} \mathrm{K}$. Nitrogen vapor densities along the saturation line are represented by $\log \rho T=3.39858-282.953 /(T-3.83)$. The fugacity function $\ln f / p$ for the saturated vapor is tabulated.
\end{abstract}

\section{Introduction}

In the course of a study of the vapor-liquid phase behavior of mixtures of oxygen and nitrogen a series of measurements has been made on the vapor pressure of pure liquid nitrogen. These measurements cover the liquid range below the normal boiling point.

\section{Description of Cryostat}

The cryostat was designed for liquid-vapor equilibrium studies of mixtures and thus contains several features not essential to the vapor-pressure studies. The following description of the apparatus covers only those portions of the apparatus essential to the measurements.

The equilibrium vessel, in which the liquid nitrogen was contained is a cylinder having walls of $1 / 8$-in. copper and an inner diameter of $1 \mathrm{in}$. The thermometer is in a well suspended from the upper lid. In these experiments the quantity of liquid nitrogen was insufficient to touch the thermometer well, so that reliance was placed on the uniform-temperature environment and the high thermal conductivity of the copper walls of the equilibrium vessel to insure that the thermometer and liquid were at the same temperature. The equilibrium vessel is suspended by thin-walled tubes within a copper can, which may be evacuated or filled with helium gas for heat transfer. This can forms a constant-temperature enclosure for the equilibrium vessel. It is completely immersed in a constant-temperature nitrogen bath. The temperature of this bath is maintained at the desired operating temperature by regulating the pressure under which it boils with the aid of a cartesian-diver manostat.

To reduce losses of liquid nitrogen from the constant-temperature nitrogen bath, and thus permit longer operation before refilling is required, the constant-temperature bath is immersed in a secondary liquid-nitrogen bath, which is allowed to boil freely at the prevailing atmospheric pressure.

The manometer tube passes through each of the liquid baths. The thermometer leads are brought through a tube into the helium-filled space surrounding the equilibrium vessel. To insure that they are at the bath temperature the leads are wound several times around the pumping tube, which projects into the helium-filled space, and are cemented to the tube.

\footnotetext{
1 This research was supported by the Air Research and Development Com-
} mand, Department of the Air Force.

\section{Temperature Measurement}

Temperatures were measured with a capsule-type platinum resistance thermometer immersed in a well in the lid of the equilibrium vessel. This thermometer was calibrated against the National Bureau of Standards provisional temperature scale below the the oxygen point $[1]^{2}$ and was checked at the oxygen point during the course of the measurements.

\section{Pressure Measurement}

The manometer used is a version of one described by Swindells, Coe, and Godfrey [2] modified in such a way as to make an absolute pressure-reading instrument. In this manometer the mercury surfaces are located by touching them with stainless-steel rods of calibrated lengths. The contacts are detected electrically, in this instance, by observing the extinction of a lighted neon bulb when a contact is made. The manometer has one fixed contact in the arm connected to the vapor-pressure apparatus. The other arm is closed and evacuated. The detecting rods are introduced into the closed arm through a mounting that can be moved vertically to bring the rod into contact with the mercury. After a contact is made, the position of the upper end of the movable rod is determined with the aid of a micrometer depth gage reading in millimeters. The manometer reads directly to $0.01 \mathrm{~mm}$, and it is possible to interpolate to about $0.002 \mathrm{~mm}$. The manometer as used in these measurements did not provide readings of this accuracy, because the temperature control of the mercury column was not sufficiently good. Errors as large as $0.015 \mathrm{~mm}$ or perhaps somewhat larger may have been introduced at times because of uncertainty in the mean temperature of the mercury column.

The measuring rods were calibrated by the Gage Section of the National Bureau of Standards. Thirtyseven quarter-inch stainless steel rods differing in length by increments of $1 \mathrm{in}$. permitted complete coverage of the pressure range. The rods have a conical lower end with a rounded tip of approximately $1 / 32$-in. radius. The upper end of each is capped by a $3 / 4$-in. sphere of bearing bronze, against which the micrometer contact is made. The under surface of the sphere forms a vacuum tight but easily demountable seal against a conical opening through the movable mounting at the top of the closed arm of the manometer.

${ }^{2}$ Figures in brackets indicate the literature references at the end of this paper. 
Mercury heights determined in this manometer were corrected to $0^{\circ} \mathrm{C}$ for thermal expansion of the rods and of mercury, and to a standard gravity of $980.665 \mathrm{~cm} \mathrm{sec}^{-2}$. The tube bore is $1 \mathrm{in}$., and so the necessity for capillary corrections was eliminated. This diameter also insures that the mercury surface is flat enough that the centering of the longer rods does not have to be closer than about $2 \mathrm{~mm}$.

A small correction to the pressure was applied to compensate for the pressure difference between the mercury surface and the liquid-nitrogen surface caused by the greater density of the cold gas in the cryostat. This correction at most amounted to 0.08 $\mathrm{mm}$ and was very nearly proportional to the pressure in the system.

\section{Material Investigated}

The nitrogen used in the experiments was Linde Air Products Company standard high-purity dry nitrogen. This was stated by the supplier to contain less than 0.005 percent of argon. A calorimetric study of the melting point of a similar sample as a function of the fraction melted indicated that liquidsoluble solid-insoluble impurities amounted to much less than 0.01 percent. The material used in the last series of vapor-pressure measurements was analyzed by mass spectrometer after the measurements had been completed and was found to contain approximately 0.01 percent of oxygen. This sample had been in the vapor-pressure apparatus for approximately 2 weeks under reduced pressure, so it is probable that the oxygen entered from the walls or by seepage through stopcock grease, and it may have entered after the measurements were completed. In any case, the maximum effect produced by this amount of oxygen would be $0.06 \mathrm{~mm}$ at $760-\mathrm{mm}$ total pressure.

\section{Experimental Procedure and Results}

In order to insure purity of the nitrogen introduced into the system, the connecting lines to the highpressure cylinder were evacuated and filled several times and left full of nitrogen at a pressure slightly greater than atmospheric. The remainder of the apparatus was then evacuated overnight at a pressure below $10^{-4} \mathrm{~mm}$. It was then filled with nitrogen, and the cryostat was cooled. Approximately 2 liters of gas was then condensed into the sample holder. The amount condensed was varied in some of the early measurements, and no effect on the measured pressures was observed. After filling the apparatus, all parts except the manometer were closed off by means of stopcocks.

It was impossible to keep the temperature absolutely steady. Drifts observed were of the order of $0.01 \mathrm{deg}$ in $5 \mathrm{~min}$ at the lower temperatures and onehalf to one-third this rate near the normal boiling point. A series of alternate temperature and pressure measurements was made over a period of 10 $\min$ to $1 / 2 \mathrm{hr}$. These were plotted as a function of time, and for each pressure reading a corresponding temperature was found by interpolation. Each value thus determined has been treated as a separate point, though in a sense the measurements of a series are not independent.

Because there was no stirring in the nitrogen constant-temperature bath, a period of 1 or $2 \mathrm{hr}$ was needed to fix the temperature of the bath at a new value and to allow equilibrium to be reestablished. It was thought to be advantageous to start the measurements at a low temperature and to allow the temperature to rise between measurements. This procedure insured that the sample vessel, which always lagged the bath in temperature, would never be at a higher temperature than any part of the bath through which the manometer tube passed.

The measurements made on several different days, and using several different fillings of nitrogen, showed no consistent differences from one another. All measurements made in runs 1, 2, and 3 are shown in table 1 . The only measurements not shown are some earlier ones in which the bath level was not properly controlled and in which the manostat regulating the bath pressure was not functioning properly. They showed large and erratic fluctuations, which did not appear again when these two factors were corrected.

Taвle 1. Vapor pressure of liquid nitrogen

\begin{tabular}{|c|c|c|c|c|c|}
\hline $\begin{array}{l}\log P \\
(\mathrm{~mm})\end{array}$ & $\begin{array}{c}T^{\circ} \mathrm{K} \\
\text { (observed) }\end{array}$ & $\begin{array}{c}\triangle T \times 10^{3} \\
\text { (observed } \\
\text { minus } \\
\text { calculated) }\end{array}$ & $\begin{array}{l}\log P \\
(\mathrm{~mm})\end{array}$ & $\begin{array}{c}T^{\circ} \mathrm{K} \\
\text { (observed) }\end{array}$ & $\begin{array}{c}\triangle T \times 10^{3} \\
\text { (observed } \\
\text { minus } \\
\text { calculated) }\end{array}$ \\
\hline \multicolumn{3}{|c|}{ Series 1} & \multicolumn{3}{|c|}{ Series 3} \\
\hline 2. 89075 & 77.5578 & -1.1 & 2. 89479 & 77. 6398 & +1.4 \\
\hline 2.89040 & 77. 5535 & +1.5 & 2. 89486 & 77. 6406 & $\begin{array}{r}1.8 \\
+0.8\end{array}$ \\
\hline 2.89037 & 77. 5521 & $\begin{array}{r}0.7 \\
+0.7\end{array}$ & 2. 89487 & 77. 6412 & $\begin{array}{r}1.2 \\
+1.2\end{array}$ \\
\hline 2. 89025 & 77.5495 & +.4 & 2. 89594 & 77. 6607 & -0.4 \\
\hline 2. 89119 & 77. 5693 & +1.7 & 2. 89611 & 77.6654 & +9 \\
\hline 2.89111 & 77.5665 & $\begin{array}{r}1.1 \\
+0.5\end{array}$ & 2. 11060 & 64. 9360 & $\begin{array}{r}0.7 \\
+0.7\end{array}$ \\
\hline 2.89114 & 77. 5678 & $\begin{array}{r}-1.2 \\
\end{array}$ & 2. 11127 & 64.9452 & +1.0 \\
\hline 2.89188 & 77. 5820 & $\begin{array}{r}+0.9 \\
\end{array}$ & 2. 11159 & 64. 9495 & $\begin{array}{r}1.0 \\
+1.0\end{array}$ \\
\hline \multicolumn{3}{|c|}{ Series 2} & $\begin{array}{l}\text { 2. } 21284 \\
\text { 2. } 24894\end{array}$ & $\begin{array}{l}66.3291 \\
66.8354\end{array}$ & $\begin{array}{l}+1.2 \\
-0.2\end{array}$ \\
\hline & & & 2. 250.58 & 66.8576 & $\begin{array}{r}7.2 \\
-1.2\end{array}$ \\
\hline 2. 83444 & 76.4686 & +1.0 & 2. 89618 & 77. 6638 & -2.1 \\
\hline 2.83450 & 76.4697 & $\begin{array}{r}+0.9 \\
\end{array}$ & 2. 89619 & 77.6642 & -1.9 \\
\hline 2. 83453 & 76.4704 & +1.1 & 2. 89618 & 77. 6644 & -1.5 \\
\hline 2. 79033 & 75.6344 & -1.6 & 2. 21036 & 66. 2920 & -1.3 \\
\hline 2. 78979 & 75.6267 & +0.8 & 2. 21138 & 66. 3088 & $\begin{array}{r}+1.3 \\
\end{array}$ \\
\hline 2. 78929 & 75.6181 & +1.5 & 2. 21457 & 66.3500 & -2.0 \\
\hline 2. 78910 & 75.6130 & -0.0 & 2. 27468 & 67. 1998 & -3.1 \\
\hline 2. 78944 & 75. 6186 & -.8 & 2. 27418 & 67. 1959 & $\begin{array}{r}0.1 \\
+0.2\end{array}$ \\
\hline 2. 56364 & 71. 6574 & +.8 & 2. 27402 & 67. 1915 & -1.9 \\
\hline 2.56370 & 71.6580 & $\begin{array}{r}.8 \\
+.8\end{array}$ & 2. 35593 & 68. 3915 & -0.7 \\
\hline 2. 35740 & 68.4412 & $\mathrm{a}+27.0$ & 2. 35591 & 68. 3916 & -.3 \\
\hline 2.35715 & 68.4386 & $a+28.2$ & 2. 35609 & 68. 3939 & -.7 \\
\hline 2. 35713 & 68.4370 & $\mathrm{a}+26.9$ & 2. 42898 & 69. 5017 & -4 \\
\hline 2. 27544 & 67. 2135 & $\begin{array}{r}+0.6 \\
\end{array}$ & 2. 42905 & 69.5036 & $\begin{array}{r}.4 \\
+.4\end{array}$ \\
\hline 2. 27547 & 67.2137 & -.8 & 2. 42917 & 69. 5054 & $\begin{array}{r}.7 \\
+.3\end{array}$ \\
\hline 2. 27556 & 67. 2137 & -2.3 & 2. 50438 & 70. 6901 & -.2 \\
\hline $\begin{array}{l}2.2000 \\
2.21875\end{array}$ & & & 2. 50457 & 70.6933 & -.1 \\
\hline 2.21875 & 66.4091 & -0.5 & 2. 50473 & 70.6966 & +.7 \\
\hline 2.21881 & 66.4102 & -1.7 & 2. 58980 & 72.0941 & +2.2 \\
\hline 2. 21894 & 66.4121 & -2.5 & 2. 58991 & 72.0952 & $\begin{array}{r}2.5 \\
+1.5\end{array}$ \\
\hline 2. 11814 & 65.0373 & $\begin{array}{r}2.0 \\
+1.5\end{array}$ & 2. 59002 & 72.0968 & +1.3 \\
\hline $\begin{array}{l}2.11014 \\
2.11837\end{array}$ & & T1.0 & 2. 69836 & 73.9597 & -1.3 \\
\hline 2.11837 & 65.0390 & +0.1 & 2. 69871 & 73.9709 & +0.7 \\
\hline 2. 11864 & 65.0419 & -.6 & 2. 69917 & 73.9797 & $\begin{array}{r}0.3 \\
+1.3\end{array}$ \\
\hline 2. 05277 & 64. 1776 & +1.5 & 2. 85437 & 76.8532 & $\begin{array}{r}1.2 \\
+3.2\end{array}$ \\
\hline 2. 05289 & 64. 1777 & 0.0 & 2. 85470 & 76.8594 & +3.0 \\
\hline 2. 05296 & 64.1778 & $\begin{array}{r}0.0 \\
-.8\end{array}$ & $\begin{array}{l}2.85472 \\
2.85465\end{array}$ & $\begin{array}{l}76.8593 \\
76.8579\end{array}$ & $\begin{array}{l}+2.5 \\
+2.5\end{array}$ \\
\hline
\end{tabular}

a Discarded by Chauvenet's criterion.

The data have been fitted by the Antoine-type equation (1)

$$
\log P(\mathrm{~mm})=6.49594-255.821 /(T-6.600) .
$$


Aside from three points at $68.4^{\circ}$, the measurements lie within a narrow band about eq (1). For these three points the observed and calculated pressures differ by very nearly $1 \mathrm{~mm}$, so it is possible that an error was made in reading the micrometer depth gage. These three points were discarded on the basis of Chauvenet's criterion. The mean deviation from eq (1) of all measurements except those specified above is $\pm 0.0012 \mathrm{deg} \mathrm{K}$, or $\pm 0.063 \mathrm{~mm}$. It is possible that a slightly better fit could be obtained by the use of an additional constant or a different functional form of an equation because there appears to be a slight cyclic trend of the deviations. An estimation of the best fit in the form of a smooth curve drawn through the deviations suggests that the mean deviation could not be reduced below $0.0010 \mathrm{deg} \mathrm{K}$ by any other simple equation.

The normal boiling point calculated from eq (1) is $77.364 \mathrm{deg}$ K. Some other experimental values are shown in table 2 [3 to 8]. The standard deviation in this temperature, which was found to be $\pm 0.0013 \mathrm{deg}$ for the present work, indicates only the internal precision of the data and does not give any indication of the reliability of the temperature scale. The values obtained by Henning and Otto [6] and by Keesom and Bijl [7] are very close to the present value. The value of $77.34 \mathrm{deg}$ reported by Friedman and White [8] is obtained from their equation. Their value is subject to an uncertainty of 0.05 to 0.07 deg because of the deviation of their equation from their experimental values in the immediate vicinity of the boiling point.

A comparison of the experimental data from several laboratories with eq (1) is shown in figure 1 . The deviations shown in table 1 have been omitted from figure 1 in order to avoid a confusion of points near the reference line. The present data are in good agreement with the data of Keesom and Bijl, showing only small systematic deviations. The rather large deviations of the data of Henning and Otto are not easy to account for because they are erratic; on the other hand, the deviations of the data of Giauque and Clayton are very systematic. The systematic deviations in the work from various laboratories are probably due to differences in the temperature scales. It is unlikely that any further improvement in the consistency of the vapor-pressure data of nitrogen will be made until the temperature scales used in various laboratories are brought into agreement in this region.

TABle 2. Normal boiling point of nitrogen

\begin{tabular}{|c|c|c|}
\hline Investigators & Date & $T_{\mathrm{B}}$ \\
\hline $\begin{array}{l}\text { Dodge and Davis [3] } \\
\text { Heuse and Otto [4] } \\
\text { Giauque and Clayton }[5] \\
\text { Henning and Otto }[6] \\
\text { Keesom and Bijl [7] } \\
\text { Friedman and White }[8] \\
\text { This research }\end{array}$ & $\begin{array}{l}1927 \\
1932 \\
1933 \\
1936 \\
1937 \\
1950 \\
1954\end{array}$ & $\begin{array}{l}{ }^{\circ} K \\
77.36 \\
77.346 \\
77.32 \\
77.352 \\
77.373 \\
77.34 \\
77.364\end{array}$ \\
\hline
\end{tabular}

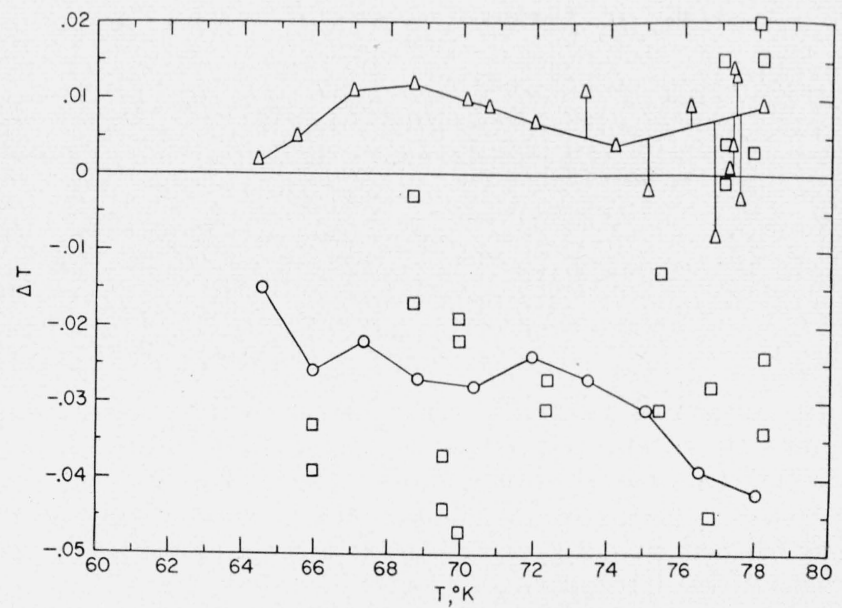

Figure 1. Deviations (observed minus calculated) of other experimental values from equation 1.

$\triangle$, Keesom and Bijl; $\bigcirc$, Giauque and Clayton; $\square$, Henning and Otto.

\section{Calculation of Saturated Vapor Volume and Fugacity}

Vapor-pressure data have at times been used for calculating the latent heat of vaporization, using the formula $\Delta H=T\left(V_{g}-V_{l}\right) d P / d T$. The vapor volume of nitrogen is, however, probably not as well known as the other quantities required in this formula. The only direct experimental measurements of this quantity were those of Mathias, Onnes, and Crommelin [9]. These were revised by Crommelin for inclusion in the International Critical Tables [10], using a reduced equation of state, but it is questionable whether any improvement resulted.

Because the heat of vaporization has been accurately measured by Furukawa and McCoskey [11], their data have been combined with the present vapor-pressure data to calculate the saturated vapor density at several temperatures. The liquid volumes used were those of Mathias, Onnes, and Crommelin. The saturated vapor density derived from the vaporpressure data may be represented by eq (2), where $\rho$ is the vapor density in grams per cubic centimeter,

$\log \rho T=3.39858-282.953 /(T-3.83)$.

TABLE 3. Saturated vapor density of nitrogen

\begin{tabular}{|c|c|c|c|c|c|}
\hline \multirow{2}{*}{$T$} & \multirow{2}{*}{$\Delta H$ (vapor) [11] } & \multicolumn{4}{|c|}{$\rho \times 10^{3}\left(\mathrm{~g} / \mathrm{cm}^{3}\right)$} \\
\hline & & 1 & 2 & 3 & 4 \\
\hline${ }^{\circ} K$ & abs j mole $e^{-1}$ & & & & \\
\hline 64.80 & - & 0.883 & & 0.89 & 0.868 \\
\hline 67.71 & - & 1. 376 & & 1. 36 & ...... \\
\hline 68.00 & 6775.0 & 1. 434 & 1. 434 & -....- & $\ldots$ \\
\hline 73. 10 & 5735. 2 & 2. 818 & 2.818 & 278 & -..... \\
\hline $\begin{array}{l}73.13 \\
77.364\end{array}$ & -55930 & $\begin{array}{l}2.828 \\
4.593\end{array}$ & 4593 & 2. 78 & - n \\
\hline $\begin{array}{l}7.364 \\
78.00\end{array}$ & $\begin{array}{l}5593.0 \\
5571.8\end{array}$ & $\begin{array}{l}4.593 \\
4.915\end{array}$ & $\begin{array}{l}4.593 \\
4.916\end{array}$ & (n) & n..... \\
\hline 78.07 & - & 4. 952 & - & 4. 90 & 4. 98 \\
\hline
\end{tabular}


TABLE 4. Fugacity function of nitrogen

\begin{tabular}{|c|c|}
\hline$T$ & $\ln f / p$ \\
\cline { 1 - 1 } \cline { 1 - 1 }${ }^{\circ} K$ & \\
64 & -0.0096 \\
66 & -.0127 \\
68 & -.0163 \\
70 & -.0205 \\
72 & -.0250 \\
74 & -.0297 \\
76 & -.0348 \\
78 & -.0409 \\
\hline
\end{tabular}

In column 1 of table 3 are shown values of vapor density calculated from eq (2). The values from which this equation was derived are shown in column 2 ; those given by Mathias, Onnes, and Crommelin are listed in column 3, and the revised values presented by Crommelin are shown in column 4 .

The densities calculated from the vapor-pressure data are seen to be intermediate between the observed and revised values of Mathias, Onnes, and Crommelin. It should be noted that the revised value for the vapor density given by Crommelin at $64.80^{\circ} \mathrm{K}$ is incompatible with the behavior of a real gas near its saturation line, as it is less than ideal gas density at this temperature and pressure.

Using eq (2) for calculating vapor volumes, the fugacity of nitrogen along the saturation line has been calculated and is shown in the form $\ln f / p$ in table 4 . There are no experimental data for this quantity derived from PVT measurements below $80^{\circ}$. However, extrapolations of higher-temperature data from various sources give values that are in some cases larger and in other cases smaller than those listed in table 4.

\section{References}

[1] H. J. Hoge and F. G. Brickwedde, J. Research NBS 22, 351 (1939) RP1188.

[2] J. F. Swindells, J. R. Coe, and T. B. Godfrey, J. Research NBS 42, 1 (1952) RP2279

[3] B. F. Dodge and H. N. Davis, J. Am. Chem. Soc. 49, 610 (1927).

[4] W. Heuse and J. Otto, Ann. Phys. [5] 14, 185 (1932).

[5] W. F. Giauque and J. O. Clayton, J. Am. Chem. Soc. 55, 4875 (1933)

[6] F. Henning and J. Otto, Phys. Z. 37, 633 (1936).

[7] W. H. Keeson and A. Bijl, Physica 4, 305 (1937).

[8] A. S. Friedman and D. White, J. Am. Chem. Soc. 7\%, 3931 (1950).

[9] E. Mathias, H. K. Onnes, and C. A. Crommelin, Koninkl. Akad. Wetenschap. Amsterdam 17, 953 (1915); Commun. Leiden, 145C.

[10] C. A. Crommelin, International Critical Tables III, 204 (McGraw-Hill Book Co., Inc., New York, N. Y., 1930)

[11] G. T. Furukawa and R. E. MeCoskey (informal communication).

Washington, May 18, 1954. 